INFLAMMATORY BOWEL DISEASE

\title{
Frequency and significance of granulomas in a cohort of incident cases of Crohn's disease
}

\section{Heresbach, J L Alexandre, B Branger, J F Bretagne, E Cruchant, A Dabadie, M Dartois-Hoguin, P M Girardot, H Jouanolle, J Kerneis, J C Le Verger, V Louvain, J Politis, M Richecoeur, M Robaszkiewicz, J A Seyrig, the ABERMAD (Association Bretonne d'Etude et de Recherche sur les Maladies de l'Appareil Digestif)}

Background and aims: Epithelioid granulomas is one of the best histological criterion for distinguishing Crohn's disease (CD) from other inflammatory bowel diseases. Few data are available on the time of occurrence of epithelioid granulomas, and the value of epithelioid granulomas in predicting outcome has been determined only in cohorts of prevalent CD cases. Our objective was to evaluate epithelioid granuloma occurrence in incident $C D$ cases and to examine the associations between epithelioid granulomas and outcome.

See end of article for authors' affiliations Patients and methods: We reviewed the histological reports of endoscopic and surgical specimens in a cohort of 188 consecutive incident CD cases seen in 1994 and 1995, and recorded the occurrence of epithelioid granulomas, isolated giant cells, and microgranulomas. Kaplan-Meier curves were plotted for time from CD diagnosis to immunosuppressive treatment or surgery, and associations between epithelioid granulomas and outcome were evaluated in a multivariate analysis. Follow up was at least five years.

Correspondence to: Service des Maladies de l'Appareil Digestif, Hôpital Pontchaillou, Rue Henri Le Guilloux, 35033-Rennes

Cedex, France;

denis.heresbach@

chu-rennes.fr

Revised version received 12 May 2004

Accepted for publication

31 May 2004

Results: Granulomas were found in 69 (37\%) patients, including $46(25 \%)$ at presentation. Median time from CD diagnosis to epithelioid granuloma detection was 0.16 (0-63) months overall, and 9.59 (0.163) months in 23 patients who became epithelioid granuloma positive during follow up. Isolated giant cells were found in $6 \%$ of patients and microgranulomas in 12\%. Epithelioid granuloma detection increased with the number of endoscopic sampling procedures; sampling site had no influence. By multivariate analysis, epithelioid granulomas were associated with surgical resection but not immunosuppressive therapy.

Conclusions: Epithelioid granulomas may separate CD into two pathological subsets and may indicate aggressive disease.

\begin{abstract}
C olorectal biopsy is helpful in distinguishing between Crohn's disease (CD) and ulcerative colitis, although this distinction. ${ }^{1-10}$ Histological guidelines for diagnosing inflammatory bowel disease (IBD) and distinguishing CD from ulcerative colitis ${ }^{5}$ have been developed. Several classification schemes list criteria for a definite, probable, or possible diagnosis, ${ }^{311} 12$ with presence of epithelioid granulomas indicating definite $\mathrm{CD}$. Although interobserver agreement for epithelioid granulomas is good, ${ }^{47}$ occurrence rates vary across series of $C D$ patients, probably as a result of differences in patient populations or in biopsy technique (for example, serial sectioning versus step sectioning). ${ }^{13}{ }^{14}$ Among patients with onset of IBD within the last year, only $12 \%$ had detectable epithelioid granulomas. ${ }^{8}{ }^{15}$ Nevertheless, a study specifically designed to compare histological findings in biopsy specimens from patients with recent onset or chronic IBD found no difference in the rate of occurrence of epithelioid granulomas. ${ }^{6}$ A trend towards a higher rate of epithelioid granulomas has been found in paediatric CD patients ${ }^{13}{ }^{16-18}$ but only cohort studies of prevalent CD cases included both children and adults. Epithelioid granulomas predicted CD outcome in several studies ${ }^{19-39}$ although they were unhelpful in assessing disease activity. ${ }^{40}$ Most of these previous studies examined surgical specimens or cross sectional collections of histological samples and used recurrence after the first resection procedure as the primary outcome variable. Moreover, outcomes were evaluated in prevalent cases of $\mathrm{CD}$, and the presence of epithelioid
\end{abstract}

granulomas was determined only in a limited number of tissue samples, usually surgical specimens as opposed to all biopsy and surgical specimens obtained since CD onset.

To evaluate the rate of occurrence and potential prognostic significance of epithelioid granulomas in $\mathrm{CD}$, we recorded the presence of epithelioid granulomas over a five year period in a large cohort of patients with incident CD, using all available specimens, and we assessed correlations between the presence of epithelioid granulomas and clinical outcome.

\section{PATIENTS AND METHODS \\ Patients}

A population based inception cohort established for an earlier study ${ }^{41}$ was used. All patients given a diagnosis of IBD during a two year period (1994-1995) were identified prospectively by gastroenterologists who maintain a registry of IBD in Brittany (ABERMAD), France. These gastroenterologists use a standardised case ascertainment procedure ${ }^{12}{ }^{40}$ and meet annually with pathologists to examine diagnostic guidelines and to update their practice.

Among patients in the registry, those with CD were identified based on well established clinical, endoscopic, radiological, and histological criteria. ${ }^{1}{ }^{11}$ During the study period, 214 patients with CD were entered into the registry. The following data were recorded for each patient: age, sex, age at diagnosis, initial and cumulative disease locations,

Abbreviations: $C D$, Crohn's disease; IBD, inflammatory bowel disease; OR, odds ratio 


\begin{tabular}{ll} 
Table 1 Characteristics of the 188 patients at inclusion \\
\hline Age (y) & $36.4(20.2)$ \\
Mean (SD) & $29(6-85)$ \\
Median (range) & $98 / 90$ \\
Sex (F/M) & $6.9(10.5)$ \\
Time from symptom onset to diagnosis (months) \\
Mean (SD) & $2(0.1-72.0)$ \\
Median (range) & $56.1(27.4)$ \\
Clinical follow up duration (months) & $67.3(0.1-92.8)$ \\
Mean (SD) & $16.8(23.2)$ \\
Median (range) & $2.6(0.1-84.0)$ \\
Histological follow up duration (months) & \\
Mean (SD) & \\
Median (range) & \\
\hline *Delay between onset and last histological sample either by endoscopic \\
or surgical procedure.
\end{tabular}

date of upper or colonic endoscopy, date of and reason for each operative procedure, date of the first course of each treatment (including salicylates, glucocorticoids, or immunosuppressive drugs such as azathioprine, methotrexate, and infliximab), occurrence of extraintestinal manifestations, and duration of follow up from CD diagnosis to final evaluation. Surgery was defined as any operation for CD but procedures were classified into several categories, and those involving small or large bowel resection were identified. The occurrence of medical events at any time during follow up was recorded. The final evaluation was performed during the second half of 2001 and consisted of obtaining data from the gastroenterologist and general practitioner, by mail and, if needed, by telephone call. These data were available for 188 (88\%) patients who form the basis for the present study.

All histological slides from endoscopic and surgical specimens were reviewed by four IBD experts for the presence of epithelioid granulomas and other histopathological features previously identified as relevant-namely, giant cells and microgranulomas ${ }^{4-7}{ }^{10}$ - defined according to our previous report ${ }^{4}$ : an epithelioid granulomas is a collection of at least five epithelioid cells with or without accompanying giant cells, and without caseating necrosis or foreign bodies. A microgranuloma is an aggregate of histiocytes and lymphocytes; giant cells are absent. Giant cells contain multiple nuclei and homogenous, fine, powdery cytoplasm without foreign bodies. Correlations were sought between histological findings, including the presence of epithelioid granulomas, and two main outcome variables-need for immunosuppressants and need for surgical resection.

Of 2600 histological specimens from 414 endoscopic biopsy or surgical procedures, 2443 were obtained from 370 sampling procedures by endoscopy and 157 from 44 surgical procedures. Because of the variation in affected bowel sites, the heterogeneous pattern of endoscopic biopsies, and absence of routine upper gastrointestinal endoscopy, we classified the histological specimens by site sampled, as follows: oesophagus, stomach, and duodenum, with 290 biopsies from 66 procedures; ileum 453 biopsies from 125 procedures; colon, 1470 biopsies from 297 procedures; and rectum, 230 biopsies from 62 procedures. This resulted in a mean of 2.2 (SD 1.2) sampling endoscopic procedures (median 2 (range 1-6)) and 14.3 (11.8) endoscopic biopsies (median 10 (range 2-74)) per patient. The 44 surgical procedures for $\mathrm{CD}$ were performed in 41 patients, 28 of them for intestinal or colonic resection and 14 for anoperineal surgery (one patient had both types of surgery). Histological features analysed were defined as previously described..$^{45}$ In an earlier study, ${ }^{4}$ we found that epithelioid granulomas, microgranulomas, and giant cells were the best predictors of $\mathrm{CD}$ and that, in a logistic regression model with a stepwise ascending procedure, these three histological features identified a distinctive histological pattern present in a subset of CD patients. Therefore, we focused the present study on these three histological findings.

\section{Statistical analysis}

Results are expressed as mean (SD) or median (range) according to the data distribution for each variable. Differences between patients with and without epithelioid granulomas were compared using the independent sample $t$ test or Wilcoxon's test for normally and non-normally distributed variables, respectively. $\chi^{2}$ tests or Fisher's exact test was used for categorical variables. A p value $<0.05$ was considered statistically significant.

Associations linking each variable to the presence of epithelioid granulomas were evaluated by determining the odds ratios (ORs) with their 95\% confidence intervals (95\% $\mathrm{CI}$ ) calculated from logistic regression coefficients and their standard errors. Times from CD diagnosis to immunosuppressive treatment or surgery were estimated using the Kaplan-Meier technique and compared using the log rank test. A Cox proportional hazards model allowed simultaneous adjustment of each variable in the model for all other variables (forced selection model). Variables with $\mathrm{p}$ values $<0$.1 were included in the Cox model. The SPSS package (version 11.0, SPSS France, 75002 Paris) was used for data management and data analysis.

\section{RESULTS}

\section{Rate of occurrence of epithelioid granulomas}

Table 1 reports the main patient characteristics. At inclusion, $46(25 \%)$ patients had epithelioid granulomas; 13 (7\%) had giant cells, which were isolated in six patients, and nine (5\%) had microgranulomas, which were isolated in four patients. At the last follow up, 69 (37\%) patients had epithelioid granulomas, 22 (12\%) had giant cells (without granulomas in 11 patients), and 22 (12\%) had microgranulomas (without granulomas in 10 patients); among these 69 patients, 48 patients had isolated granulomas without giant cells or microgranulomas. Of the 69 patients with epithelioid granulomas, 49 were detected in endoscopic biopsies only, 14 in surgical specimens only, and six in both specimen types; in these six patients, granulomas were observed for the first time on endoscopic biopsies and surgical samples in four and two cases, respectively. Therefore, granulomas were observed for the first time on endoscopic biopsies and on surgical samples in 53 and 16 patients, respectively.

Epithelioid granulomas were found in 25/98 (26\%) patients investigated by colonoscopy only, in 19/54 (35\%) patients investigated by both upper gastrointestinal endoscopy and colonoscopy, and in 25/35 (71\%) surgical specimens (one patient was investigated only by upper gastrointestinal endoscopy and small bowel contrast). Epithelioid granulomas were found in $6 \%, 16 \%, 14 \%, 25 \%$, and $16 \%$ of biopsies from the upper gastrointestinal tract, ileum, right colon, left colon, and rectum, respectively, and in $8 \%, 21 \%, 16 \%, 27 \%$, and $23 \%$ of patients with biopsies from these sites, respectively. The 69 patients with epithelioid granulomas underwent 1-6 procedures for biopsies during follow up: the proportions of patients with epithelioid granulomas were $35 \%, 40 \%, 45 \%, 44 \%, 63 \%$, and $25 \%$ in the subgroups defined by the number of procedures, from 1 to 6 , respectively.

Mean time to granuloma development was 0.16 months (range 0-63) in the 69 patients overall and 9.59 months (range 0.1-63) in the 23 patients whose granulomas developed after the diagnosis of CD. In the 69 patients with granuloma, 163 sampling procedures were done in total (including endoscopic biopsies and surgery), of which 95 $(58 \%)$ showed granulomas. Among these 69 patients, the 


\begin{tabular}{|c|c|c|c|}
\hline & $\begin{array}{l}\text { No of granulomas } \\
\text { at inclusion } \\
\text { ( } n=46 \text { ) }\end{array}$ & $\begin{array}{l}\text { Granulomas found } \\
\text { during follow up } \\
(n=23)\end{array}$ & $\begin{array}{l}\text { Granulomas at last } \\
\text { follow up } \\
(\mathrm{n}=69)\end{array}$ \\
\hline \multicolumn{4}{|l|}{ No of biopsies* } \\
\hline Mean (SD) & $16.5(14.4)$ & $18.2(11.7)$ & $17.2(13.5)$ \\
\hline Median (range) & $13(2-74)$ & $16(4-41)$ & $14(2-74)$ \\
\hline \multicolumn{4}{|c|}{ No of sampling procedures } \\
\hline Mean (SD) & $3.2(1.2)$ & $3.2(1.2)$ & $2.5(1.3)$ \\
\hline Median (range) & $2(1-6)$ & $3(2-5)$ & $2(1-6)$ \\
\hline \multicolumn{4}{|c|}{ Histological follow up duration (months) } \\
\hline Mean (SD) & $23.6(27.5)$ & $33.8(27.1)$ & $27.0(27.6)$ \\
\hline Median (range) & $7.8(0-76)$ & $33.8(0-84)$ & $14.4(0-84)$ \\
\hline \multicolumn{4}{|c|}{ Time to granuloma detection (months) } \\
\hline Mean (SD) & $0.19(0.76)$ & $18.14(20.26)$ & $6.17(14.34)$ \\
\hline Median (range) & $0.09(0-3.78)$ & $9.59(0-63)$ & $0.16(0-68.0)$ \\
\hline
\end{tabular}

likelihood that granulomas would be found by endoscopic or surgical procedures performed after a granuloma positive procedure was $44 \%(23 / 52)$. Of the 69 patients, 52 underwent at least two sampling procedures; of these 52 patients, 13 (13/ $52,25 \%$ ) were found to have granulomas after two procedures; three and four of 29 patients who had at least three procedures had granulomas after two and three procedures, respectively; four, three, and two of 15 patients who had at least four procedures had granulomas after two, three, or four procedures, respectively; and two of seven patients who had five procedures had granulomas after two, three, four, or five procedures of the 69 patients with granulomas, 17, 23, 14, 8, and 6 underwent one, two, three, four, and five sampling procedures (one patient had six procedures); the proportions with granulomas by all sampling procedures were $100 \%(17 / 17), 22 \%(5 / 23), 4 \%(2 / 14)$, $16 \%(1 / 6)$, and $12 \%(1 / 8)$.

Twenty two patients had giant cells (without granulomas in $50 \%$ of cases). Giant cells were found at diagnosis in 13

Table 3 Comparison of the 69 patients with and 119 patients without granulomas

\begin{tabular}{|c|c|c|}
\hline & $\begin{array}{l}\text { Granulomas } \\
(\%)(n=69)\end{array}$ & $\begin{array}{l}\text { No granulomas } \\
(\%)(n=119)\end{array}$ \\
\hline \multicolumn{3}{|l|}{ Age (y) } \\
\hline Mean (SD) & $34.2(20.6)$ & $37.7(19.9)$ \\
\hline Median (range) & $25.8(5.9-85.9)$ & $30.3(8.7-82.1)$ \\
\hline \\
\hline $\begin{array}{l}\text { Follow up duration (months) } \\
\text { Mean (SD) }\end{array}$ & $57.8(27.2)$ & $55.4(27.6)$ \\
\hline Median (range) & $66(0.1-88)$ & $67(0-93)$ \\
\hline \multicolumn{3}{|l|}{ Anoperineal involvement } \\
\hline Initial & $9(20)^{*}$ & $9(6)$ \\
\hline At last follow up & $20(29)^{*}$ & $13(13)$ \\
\hline \multicolumn{3}{|l|}{ Extraintestinal manifestations } \\
\hline Initial & $5(11)$ & $15(11)$ \\
\hline At last follow up & $19(28)$ & $32(27)$ \\
\hline Glucocorticoid therapy & $48(70)^{* * *}$ & $47(40)$ \\
\hline Immunosuppressant agents & $17(25)$ & $16(13)$ \\
\hline Patients with surgery for $C D$ & $25(36)^{* * *}$ & $16(13)$ \\
\hline $\begin{array}{l}\text { Patients with surgical bowel } \\
\text { resection }\end{array}$ & $18(28)^{* * *}$ & $10(8)$ \\
\hline $\begin{array}{l}\text { Patients with anoperineal } \\
\text { surgery }\end{array}$ & $8(12)$ & $6(5)$ \\
\hline No of anoperineal surgery & $14(20)^{\star \star \star}$ & $7(6)$ \\
\hline Hospitalisation for CD flare up & $29(42)^{*}$ & $31 / 119(26)$ \\
\hline Death & $4(5.8)$ & $3(2.5)$ \\
\hline $\begin{array}{l}C D, \text { Crohn's disease. } \\
{ }^{*} p<0.05 ;{ }^{* * *} p<0.001 .\end{array}$ & & \\
\hline
\end{tabular}

patients (5/46 and 8/142 patients with and without granulomas, respectively) and during follow up in nine patients (5/69 and 4/119 with and without granulomas, respectively). Median time to giant cell detection was 0.18 months (range 0-67) overall, $0.16(0-67)$ months in 10 patients with granulomas (10/69), and $0.19(0-51)$ months in 12 patients without granulomas (12/119). Of nine patients with giant cell detection during follow up, four (4/119) had no granulomas at any time and had a median time to giant cell detection of 34 months (range 2-51), and four (4/23) had granuloma development during follow up and a median time to giant cell detection of 48 months (range 0.1-65). One patient had granulomas at presentation. Among the 69 patients with granulomas, five had giant cell detection during follow up; among these five patients, three had giant cells detected by the biopsy procedure that detected granulomas; in one patient the giant cells were found after a later biopsy procedure and in another patient after a biopsy procedure performed 12 months earlier. Microgranulomas were found in nine $(5 \%)$ patients at inclusion, of whom five also had granulomas, and in $22(12 \%)$ patients at the last follow up, of whom 12 also had granulomas.

Finally, isolated granulomas, giant cells, and microgranulomas were found in 48,7 , and 6 patients, respectively,

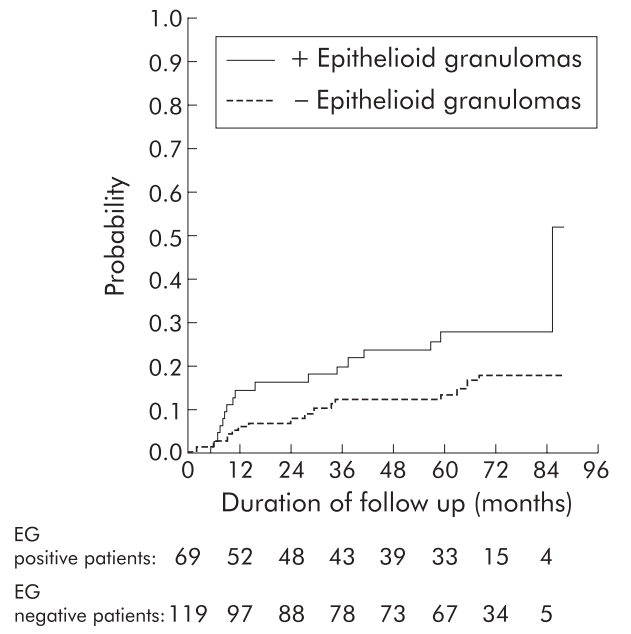

Figure 1 Time to immunosuppressive treatment in 69 patients with and 119 without epithelioid granulomas (EG). 


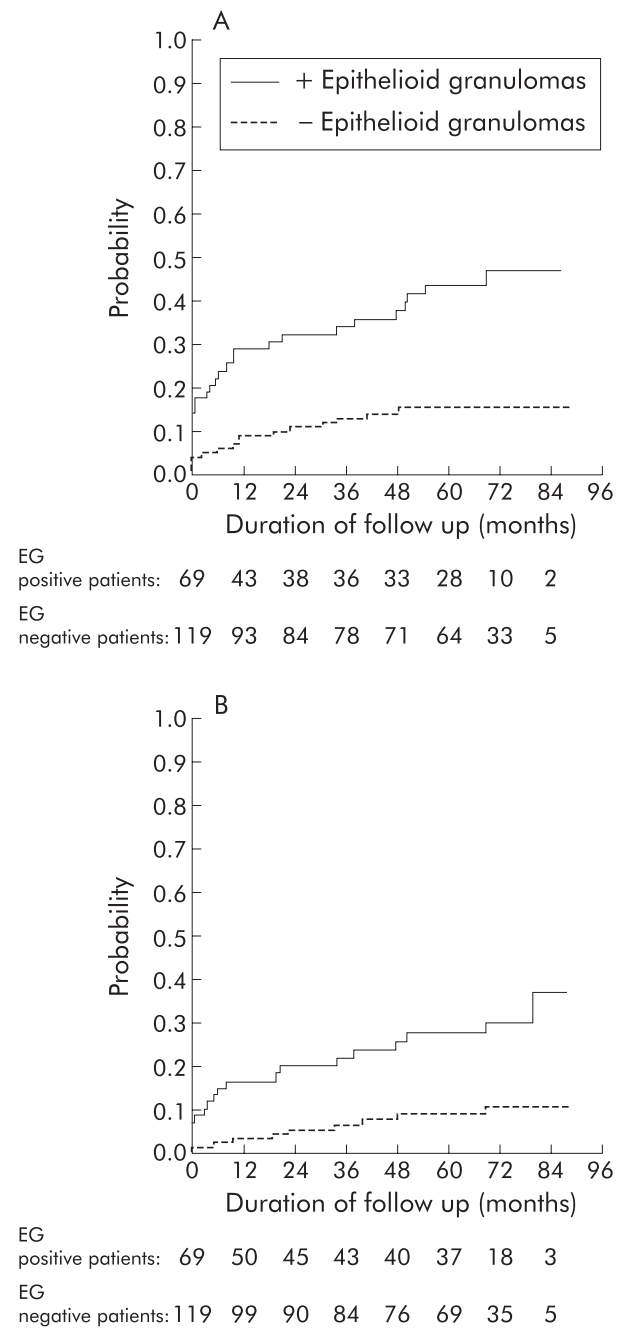

Figure 2 Time to first (A) surgery for Crohn's disease or (B) small bowel or colon resection in 69 patients with and 119 without epithelioid granulomas (EG).

whereas 17 patients had either giant cells or microgranulomas without granulomas at inclusion or during follow up. Duration of follow up of these 17 patients was 59 (23) months compared with 58 (27) (NS) and 61 (27) (NS) months in the 69 and 48 patients with granulomas or isolated granulomas.

\section{Implications of epithelioid granulomas}

The 69 patients with granulomas had a significantly larger median number of biopsies (14 (range 2-74)) than the 119 patients without granulomas at the last follow-up ( 9 (range $2-56))(\mathrm{p}<0.01)$ (table 2$)$. In the 23 patients in whom granulomas were detected during follow up, the median number of biopsies was 16 (range 4-41) compared with 9 (range 2-56) in the 119 patients without granulomas (table 2). The median number of sampling procedures (endoscopic biopsies or surgery) was 2 (range $1-6$ ) in the 69 patients with granulomas and $2(1-6)$ in the 119 patients without granulomas $(\mathrm{p}<0.005)$. In the 23 patients with granuloma detection during follow up, the median number of sampling procedures was 3 (range 2-5) compared with 2 $(1-6)$ in the 119 patients without granulomas $(\mathrm{p}<0.0001)$

Median histological follow up duration (that is, time between inclusion and last histological samples) was significantly longer in the 69 patients with granulomas
(14.4 months (range 0-84)) than in the 119 patients without granulomas (3.2 months (range 0-73); p<0.009) (table 2). Nevertheless, the median histological follow up duration in the 119 patients without granulomas was significantly longer than the median time to first granuloma detection in the 69 patients with granulomas (3.18 months (0-73) $v$ 0.16 months $(0-68)$, respectively; $p<0.0001$ ) and was similar to the median time to granuloma detection in the 23 patients in whom granulomas were absent at presentation but were detected during follow up (3.18 months (0-73) $v$ 9.59 months $(0-63) ; \mathrm{p}=0.15)$.

Compared with the 119 patients without granulomas, the 69 patients with granulomas were more likely to have anoperineal involvement at presentation or at the last follow up, systemic glucocorticoid therapy, immunosuppressive therapy, and admissions for CD flares (table 3). Bowel resection was performed in a significantly larger proportion of patients with than without granulomas (19/69 (27.5\%) $v$ $10 / 119(8.4 \%)$, respectively; $\mathrm{p}<0.001)$; in these two groups, colonic resection was performed in five and three patients, small bowel resection in six patients and one patient, and ileocolonic resection in seven and six patients, respectively. In addition, anoperineal surgery was performed in 8/69 (11.6\%) patients with granulomas (14 procedures) and in 6/119 $(5.0 \%)$ patients without granuloma (seven procedures). Anoperineal involvement at the last follow up (17/53 $v$ $3 / 16)$, systemic glucocorticoid therapy (39/53 $v 9 / 16)$, and immunosuppressive therapy $(13 / 53 v 4 / 16)$ were not different in 53 and 16 patients with granulomas observed for the first time in endoscopic biopsies or surgical samples, respectively, and use of immunosuppressants occurred no more often or sooner during follow up in these 53 and 16 patients (log rank test, NS).

A trend towards earlier use of immunosuppressants (azathioprine and/or methotrexate and/or infliximab) was noted in the 69 patients with granulomas compared with the 119 patients without granulomas (log rank test, $\mathrm{p}<0.06$ ) (fig 1). Both bowel resection (fig 2B) and any abdominal or proctological surgery for CD (fig 2A) occurred significantly more often and earlier during follow up in the 69 patients with granulomas than in the 119 patients without granulomas. Bowel resection and/or immunosuppressive therapy occurred significantly more often and earlier in the 69 patients with granulomas than in the 119 without granuloma (log rank test, $\mathrm{p}<0.001$ ) (fig 3 ).

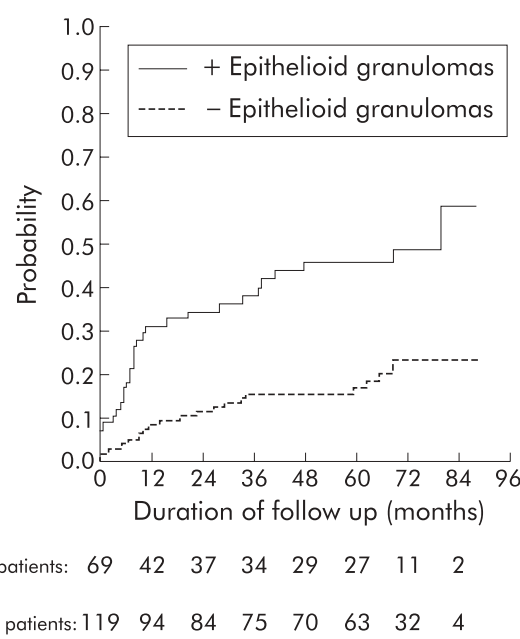

Figure 3 Time to immunosuppressive drug therapy or to bowel resection in 69 patients with and 119 patients without epithelioid granulomas (EG). 


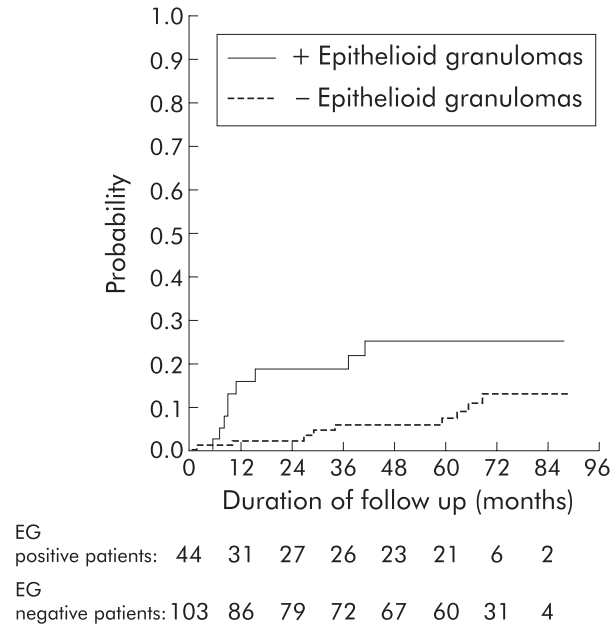

Figure 4 Time to immunosuppressive drug therapy in 44 patients with granulomas and 103 patients without epithelioid granulomas (EG).

We also compared the prognosis of patients with granulomas observed for the first time on endoscopic biopsies $(n=53)$ with patients without granulomas at inclusion or during follow up $(\mathrm{n}=119)$. Anoperineal involvement $(17 / 53$ $v 13 / 119 ; \mathrm{p}<0.0005)$, glucocorticoid therapy $(39 / 53 v 47 / 119$; $\mathrm{p}<0.0001)$, and immunosuppressant use (13/53 $v 16 / 119$; $\mathrm{p}<0.05$ ) were always significantly more frequent in 53 patients with granulomas on endoscopic biopsies than in patients without granulomas. Moreover, immunosuppressive treatment (log rank test, $\mathrm{p}<0.06$ ) and time to immunosuppressive drug therapy or to bowel resection (log rank test, $\mathrm{p}<0.05$ ) tended to occur more often and earlier in these 53 compared with the 119 patients without granulomas. Finally, to definitively exclude dependence of granuloma diagnosis on surgical sampling, we analysed the predictive value of granulomas for immunosuppressive therapy in patients who had not undergone surgery: in these 147 cases, 44 and 103 were patients with and without granulomas, respectively. Using the Kaplan-Meier technique, the rate of immunosuppressive therapy was higher in patients with granulomas than in the 103 patients without granulomas (log rank test, $\mathrm{p}<0.03$ ) (fig 4).

In the multivariate model (table 4) with epithelioid granulomas as the dependent variable, the following covariates were introduced: follow up duration, number of endoscopic or surgical procedures, number of biopsies during follow up, presence of anal or perineal disease, and age at diagnosis. Presence of epithelioid granulomas $(p<0.005)$ as well as age at diagnosis $(\mathrm{p}<0.05)$ independently predicted surgery for CD (table 4) but epithelioid granulomas alone predicted surgical resection $(\mathrm{p}<0.03)$. Only age at diagnosis was an independent predictor of immunosuppressive treatment $(\mathrm{p}<0.001)$.

\section{DISCUSSION}

In this study, we found epithelioid granulomas in $25 \%$ of CD patients at presentation and in $37 \%$ cumulatively by the end of the follow up period. Both endoscopic and surgical histological reports were reviewed by IBD experts, suggesting that the high rate of epithelioid granulomas in our population cannot be ascribed to overdiagnosis resulting from lack of experience with the histological features of epithelioid granulomas in CD. The serial sectioning method ${ }^{14} 4243$ has been reported to increase the granuloma detection rate by $50 \%$ (nine $v$ six patients). However, comparisons of the serial and step sectioning methods in CD were performed in small groups of patients, they failed to specify the timing of sampling relative to the clinical course of CD (time from CD diagnosis to the biopsy showing granulomas and age at $\mathrm{CD}$ onset), and took only rectal biopsies into account. ${ }^{14} 42$ Although the exact number of slides was not recorded in the present study, all histological samples were processed according to the serial sectioning method. Therefore, 20-30 slides of each paraffin block were examined, and this rule was adopted during the ABERMAD annual meeting and medical education from our first study on this topic. ${ }^{11}$

For our study, we used a population based IBD registry to avoid patient selection on criteria likely to bias the granuloma occurrence rate. In addition, we reviewed both surgical and endoscopic specimens, as granuloma occurrence rates in earlier studies varied widely across these two categories (from $37 \%$ to $82 \%$ in surgical specimens ${ }^{19-30} 33$ and from $14 \%$ to $56 \%$ in endoscopic biopsies). ${ }^{4-713} 14$ 16-18 31-34 42-45 46 When both surgical specimens and endoscopic biopsies were examined, the granuloma occurrence rate ranged from $26 \%$ to $73 \% .{ }^{13}$ Interestingly, in surgical studies, the highest rate $(82 \%)$ was found in a paediatric cohort ${ }^{17}$ and the lowest $(22 \%)$ in patients with CD onset after 50 years of age. ${ }^{29} \mathrm{~A}$ negative correlation has been reported between patient age at study inclusion and granuloma rate in several surgical specimen studies ${ }^{23} 2744$ and one endoscopic biopsy study, ${ }^{45}$ although this last finding was not confirmed in subsequent work by the same group. ${ }^{16}$ Moreover, a single study, which examined surgical specimens, ${ }^{44}$ found that CD onset occurred at a younger age in patients with epithelioid granulomas. Whether the higher granuloma rate reported in younger CD patients is attributable to earlier CD onset in patients with granulomas, to a shorter time from CD onset to sampling, or to both factors remains unclear. In our study, age at CD onset

\begin{tabular}{|c|c|c|c|}
\hline Covariate & $\begin{array}{l}\text { Immunosuppressive } \\
\text { treatment } \\
\text { (RR }(95 \% \mathrm{CI}))\end{array}$ & $\begin{array}{l}\text { Surgery for CD } \\
\text { (RR }(95 \% \mathrm{CI}) \text { ) }\end{array}$ & $\begin{array}{l}\text { Surgical resection } \\
\text { (RR }(95 \% \mathrm{CI}) \text { ) }\end{array}$ \\
\hline Duration of follow up & $1.0(0.98-1.02)$ & $1.0(0.59-1.02)$ & $1.00(0.99-1.03)$ \\
\hline $\begin{array}{l}\text { No of endoscopic or surgical } \\
\text { procedures }\end{array}$ & $1.15(0.80-1.66)$ & $2.09(1.57-2.79)^{\star \star * \star *}$ & $2.46(1.73-3.50)^{\star * * * *}$ \\
\hline No of biopsies $\dagger$ & $0.99(0.57-1.03)$ & $0.93(0.89-0.97)^{\star \star \star}$ & $0.94(0.91-0.98)^{* * *}$ \\
\hline Anal or perineal CD & $0.98(0.43-2.19)$ & $0.46(0.21-1.01)$ & $1.33(0.49-3.63)$ \\
\hline Age at diagnosis & $0.95(0.92-0.98)^{\star \star \star \star \star *}$ & $0.98(0.96-0.99)^{* *}$ & $0.99(0.97-1.01)$ \\
\hline Epithelioid granuloma & $1.45(0.68-3.13)$ & $3.33(1.41-7.90)^{\star \star \star \star}$ & $3.23(1.13-9.26)^{*}$ \\
\hline
\end{tabular}


was similar in patients with and without granulomas, suggesting selection bias as the explanation for the agegranuloma correlation found in earlier studies; nevertheless, we included age at $\mathrm{CD}$ onset among the covariates in our multivariate model.

Our results are in accordance with granuloma rates of 32\%, $45 \%$, and $35 \%$ in incident cases from epidemiological registries. ${ }^{13}$ Few studies have examined histological features or granuloma rates according to time since IBD onset. ${ }^{6}{ }^{8}$ In one study, granulomas were detected in 5 of $11(45 \%)$ and 3 of $4(75 \%)$ CD patients with follow ups shorter and longer than three months since CD onset. ${ }^{6}$ Our data suggest that a diagnosis of definite CD may be made only after one year of histological follow up as the median time to granuloma detection was 0.16 months in our 69 patients with granulomas at any time and 9.59 months in the 23 patients with granulomas detected during follow up but not at presentation.

Influence of the sampling site on granuloma occurrence rate would be expected. However, no marked difference was found between the bowel wall (37-78\%) and the lymph nodes $(20-42 \%)^{13} 47$ although granuloma density increased from the ileum to the anus. ${ }^{48}$ Moreover, the granuloma rate was not influenced by the site of CD lesions ${ }^{19}{ }^{45}$ : no noticeable differences in granuloma rates were found across bowel sites of $\mathrm{CD}$ involvement. In surgical cohorts, granulomas were found in $46-57 \%$ of ileal specimens and in $20-70 \%$ of colonic specimens. ${ }^{23-30}$ Granuloma rates in endoscopic cohorts were $17-30 \%{ }^{45}$ in ileocolonic CD and $13-16 \%$ in colonic CD. Among the patients in our study who had biopsies taken from the upper gastrointestinal tract, these showed granulomas in $8 \%$ of cases, a proportion in accordance with the $7-50 \%$ range in previous studies. ${ }^{49-52}$ Despite the median number of biopsies being larger in the 69 patients with granulomas than in the 119 patients without granulomas, the number of biopsies in the 23 patients with granulomas only detected during follow up was not different from those in the 46 patients with granulomas at inclusion. Moreover, the median number of biopsies in these 119 and 23 patients was above five (nine and 16, respectively). No further increase in the granuloma rate was noted when the number of biopsies increased above five or the number of endoscopic sampling procedures increased above three. ${ }^{45}$

Few studies have reported the proportions of CD patients with isolated giant cells. In our study, the proportion of patients with giant cells increased from $7 \%$ to $12 \%$ between presentation and the last follow up, and in half of these patients giant cells were isolated, yielding a $6 \%$ rate at the last follow up. In a retrospective study of prevalent IBD, well defined epithelioid granulomas or isolated giant cells were strongly associated with a diagnosis of CD when found at a distance from the crypts $^{53}$; among 19 patients with CD confirmed by histological and clinical findings, 10 had epithelioid granulomas and four had giant cells, which were isolated in three $(3 / 19,16 \%)$. The interpretation of crypt associated epithelioid granulomas has not been agreed. In one study, 10 of 14 patients with crypt associated granulomas had $\mathrm{CD}^{54}$ Nevertheless, the prevailing opinion is that free standing epithelioid granulomas and giant cells characterise $\mathrm{CD}$ whereas the same features associated with crypts indicate granulomatous cryptitis, which is presumably a foreign body reaction to mucin extrusion after crypt rupture. Granulomatous cryptitis was described in six of 23 patients with diverticular disease associated chronic colitis ${ }^{55}$ and in 25 of 29 specimens with sigmoid diverticulitis ${ }^{56}$; however, crypt associated granulomas and granulomatous cryptitis were associated with true granulomas throughout the wall and serosal fat, a clear difference from foreign body reactions to faecal material, ${ }^{57}{ }^{58}$ suggesting that diverticular disease and CD may be associated.

Identification of microgranulomas relies only on morphological analysis..$^{4-6} 1046$ In contradiction with the initial hypothesis put forward about microgranulomas, ${ }^{46}$ there is no convincing evidence that these lesions develop immediately before epithelioid granuloma formation. Microgranulomas are uncommon in acute onset CD $(10 \%) .{ }^{10}$ Moreover, microgranulomas have been found in only $12 \%{ }^{46}$ to $24 \%{ }^{4}$ of CD patients, and have been reported in other inflammatory diseases, including ulcerative colitis, with a rate of $5-7 \%,{ }^{4}{ }^{10} 58$ and in infectious colitis. ${ }^{43} 58$ Our data confirm the low rate of microgranulomas in CD patients and the absence of a marked increase in this rate between presentation $(5 \%)$ and the last follow up (12\%).

Clinical features and outcome in CD patients with and without epithelioid granulomas have received little attention. Earlier CD onset was associated with more frequent CD flares, ${ }^{59}$ a positive family history, ${ }^{60}$ positive tests for antiSaccharomyces cervisiae antibodies, ${ }^{61}$ presence of HLA DR7, ${ }^{62}$ extensive jejunal and ileal involvement with $\mathrm{CD}^{63}$ upper gastrointestinal involvement, ${ }^{64}$ and a need for at least one surgical procedure. ${ }^{64}{ }^{65}$ Presence of epithelioid granulomas in CD patients was strongly associated with a higher rate of postoperative recurrence (that is, with a need for two surgical procedures). ${ }^{23} 3048$ Among studies that found no correlation between postoperative recurrence and prior presence of epithelioid granulomas, most based the diagnosis of recurrence on clinical criteria, and only two studies ${ }^{24} 25$ obtained confirmation of the diagnosis by surgery. In an early paediatric cohort, ${ }^{18}$ including $56 \mathrm{CD}$ patients, presence of epithelioid granulomas (33\% of patients) was associated with a greater likelihood of ileal involvement, perineal disease, and surgery for CD. A more recent study ${ }^{66}$ of 82 prevalent CD cases found no difference between patients with $(26 \%)$ and without epithelioid granulomas regarding the number of patients with extraintestinal CD manifestations, perineal disease, and/or fistulas; among 82 patients, 42 were followed up for longer than one year, and neither the number nor the severity of CD flares during the period differed between the two groups. Finally, two studies evaluated the significance of histological findings as predictors of CD outcome; one sought to identify histological features distinguishing patients with penetrating or stricturing CD lesions from those without complications ${ }^{67}$ and another looked for histological patterns predicting relapse of ulcerative colitis. ${ }^{68}$ These two studies tested 34 and 14 features, respectively. Granulomas did not predict complications of $\mathrm{CD}$. Our data from CD patients suggest that epithelioid granulomas may be associated with a more aggressive course and may independently predict surgical treatment. However, granulomas did not predict the use of immunosuppressive therapy which was associated only with early age at CD onset. There is no clear explanation for this last finding. Conceivably, a contributing factor may be differences in practice among gastroenterologists regarding the choice between immunosuppressive drugs and surgery, as presence of granulomas independently predicted immunosuppressive therapy and/or surgical resection in our CD patients (OR 2.25 (95\% CI 1.13-4.43)).

In conclusion, this study supports the hypothesis that epithelioid granulomas characterise a patient subset with a more aggressive clinical course but without earlier onset of CD or an increased risk of systemic manifestations. Our data also suggest that epithelioid granulomas may be a valuable predictor of the need for more aggressive management in CD patients. This possibility requires further investigation to provide targeted therapy according to the presence or absence of granulomas in CD. 


\section{ACKNOWLEDGEMENTS}

We thank all the ABERMAD members who participated in this study. This work was supported by a grant from the French National Society of Gastroenterology (SNFGE 1999) and from Ferring SA.

\section{Authors' affiliations}

D Heresbach, J L Alexandre, B Branger, J F Bretagne, E Cruchant, A Dabadie, M Dartois-Hoguin, P M Girardot, H Jouanolle, J Kerneis, J C Le Verger, V Louvain, J Politis, M Richecoeur, M Robaszkiewicz, J A Seyrig, ABERMAD, Pontchaillou Teaching Hospital, Rennes, France Conflict of interest: None declared.

$A B E R M A D$ is a non-profit organisation for research on gastrointestinal diseases, affiliated with the Pontchaillou Teaching Hospital, Rennes, France.

\section{REFERENCES}

1 Lennard-Jones JE. Classification of inflammatory bowel disease. Scand J Gastroenterol 1989;24:2-6.

2 Lennard-Jones JE, Lockhart-Mummery HE, Morson BC. Clinical and pathological differentiation of Crohn's disease and proctocolitis. Gastroenterology 1968;54:1162-9.

3 Bernades $P$, Hecketsweiler $P$, Benozio $M$, et al. Proposition d'un système de critères pour le diagnostic des entérocolites inflammatoires cryptogénétiques (maladie de Crohn et rectocolite hémorragique). Gastroenterol Clin Biol 1978;2:1047-54

4 Le Berre N, Heresbach D, Kerbaol M, et al. Histological discrimination of idiopathic inflammatory bowel disease from other types of colitis. J Clin Pathol 1995:48:749-53.

5 Seldenrijk CA, Morson BC, Meuwissen SGM, et al. Histopathological evaluation of colonic mucosal biopsy specimens in chronic inflammatory bowel disease: diagnostic implications. Gut 1991;32:1514-20.

6 Surawicz CM, Haggitt RC, Husseman M, et al. Mucosal biopsy diagnosis of colitis: acute self-limited colitis and idiopathic inflammatory bowel disease. Gastroenterology 1994;107:755-63.

7 Theodossi A, Spiegelhalter DJ, Jass J, et al. Observer variation and discriminatory value of biopsy features in inflammatory bowel disease. Gut 1994:35:961-8

8 Schumacher G, Kollberg B, Sandstedt B. A prospective study of first attacks of inflammatory bowel disease and infectious colitis. Histologic course during the first year after presentation. Scand J Gastroenterol 1994;29:318-32.

9 Tanaka. M, Riddell RH, Saito H, et al. Morphologic criteria applicable to biopsy specimens for effective distinction of inflammatory bowel disease from other forms of colitis and of Crohn's disease from ulcerative colitis. Scand J Gastroenterol 1999;34:55-67.

10 Jenkins D, Balsitis M, Gallivan S, et al. Guidelines for the initial biopsy diagnosis of suspected chronic idiopathic inflammatory bowel disease. The British Society of Gastroenterology Initiative. J Clin Pathol 1997;50:93-105.

11 Garland CF, Lilienfeld AM, Mendeloff Al, et al. Incidence rates of ulcerative colitis and Crohn's disease in fifteen areas of the United States. Gastroenterology 1981;81:1115-24.

12 Gower-Rousseau C, Salomez JL, Dupas JL, et al. Incidence of inflammatory bowel disease in Northern France (1988-1990). Gut 1994;35:1433-8

13 Heresbach D, Heresbach-Le Berre N, Ramée MP, et al. Fréquence et valeur pronostique du granulome épithélioïde au cours des maladies inflammatoires chroniques de l'intestin. Gastroenterol Clin Biol 1999:23:1376-87.

14 Surawicz CM, Meisel JL, Ylvisaker T, et al. Rectal biopsy in the diagnosis of Crohn's disease: value of multiple biopsies and serial sectioning. Gatroenterology 1981;81:66-71.

15 Schumacher G, Sandstedt B, Möllby R, et al. Clinical and histologic features differentiating non-relapsing colitis from first attacks of inflammatory bowel disease. Scand J Gastroenterol 1991;26:151-61.

16 Schmitz-Moormann P, Schäg M. Histology of the lower intestinal tract in Crohn's disease of children and adolescents. Multicentric paediatric Crohn's disease study. Pathol Res Pract 1990;186:479-84.

17 Chong SKF, Blackshaw AJ, Boyle S, et al. Histological diagnosis of chronic inflammatory bowel disease in childhood. Gut 1985;26:55-9.

18 Markowitz J, Kahn E, Daum F. Prognostic significance of epithelioid granulomas found in rectosigmoid biopsies at the initial presentation of pediatric Crohn's disease. J Pediatr Gastroenterol Nutr 1989;9:182-6.

19 Van Patter WN, Bargen JA, Dockerty MB, et al. Regional enteritis. Gastroenterology 1954;26:347-75

20 Antonius JL, Gump FE, Lattes R, et al. A study of certain microscopic features in regional enteritis, and their possible prognostic significance. Gastroenterology 1960;38:889-905.

21 Kyle J. Prognosis after ileal resection for Crohn's disease. Br J Surg 1971;58:735-7.

22 Gump FE, Sakellariadis $P$, Wolff $M$, et al. Clinical-pathological investigation of regional enteritis as a guide to prognosis. Ann Surg 1971;176:233-42.

23 Assarsson N, Räf L. Incidence of granuloma in Crohn's disease. Acta Chir Scand 1974;140:249-51.

24 Glass RE, Baker WNW. Role of the granuloma in recurrent Crohn's disease. Gut 1976;17:75-7

25 Homan WP, Gray GF, Dineen P. Granulomas in Crohn's disease. Lancet 1978;i: 112.
26 Wolfson DM, Sachar DB, Cohen A, et al. Granulomas do not affect postoperative recurrence rates in Crohn's disease. Gastroenterology 1982;83:405-9.

27 Heimann TM, Miller F, Martinelli G, et al. Correlation of presence of granulomas with clinical and immunologic variables in Crohn's disease. Arch Surg 1988;123:46-8.

28 Kelly JK, Sutherland LR. The chronological sequence in the pathology of Crohn's disease. J Clin Gastroenterol 1988;10:28-33.

29 Roberts PL, Schoetz DJ, Pricolo R, et al. Clinical course of Crohn's disease in older patients. A retrospective study. Dis Colon Rectum 1990;33:458-62.

30 Anseline PF, Wlodarczyk J, Murugasu R. Presence of granulomas is associated with recurrence after surgery for Crohn's disease: experience of a surgical unit. Br J Surg 1997;84:78-82.

31 Griffiths AM, Wesson DE, Shandling B, et al. Factors influencing postoperative recurrence of Crohn's disease in childhood. Gut 1991;32:491-5.

32 Meessen JP, Jouret-Mourin A, Vanheuverzwyn R, et al. Apport des biopsies rectales et coliques dans le diagnostic de la maladie de Crohn. Acta Gastroenterol Belg 1987;11:211-17.

33 Smedh K, Olaison G, Franzén L, et al. The endoscopic picture reflects transmural inflammation better than endoscopic biopsy in Crohn's disease. Eur J Gastroenterol Hepatol 1996:8:1189-93.

34 Pötzi R, Walgram M, Lochs $\mathrm{H}$, et al. Diagnostic significance of endoscopic biopsy in Crohn's disease. Endoscopy 1989;21:60-2.

35 Keller KM, Bender SW, Kirchmann H, et al. Diagnostic significance of epithelioid granulomas in Crohn's disease in children. J Pediatr Gastroenterol Nutr 1990;10:27-32.

36 Trnka YM, Glotzer DJ, Kasdon EJ, et al. The long-term outcome of restorative operation in Crohn's disease. Influence of location, prognostic factors and surgical guidelines. Ann Surg 1982;196:345-55.

37 Soffley A, Myren J, Clamp SE, et al. Factors affecting recurrence after surgery for Crohn's disease. Scand J Gastroenterol 1988;23:31-4.

38 Allison MC, Hamilton SJ, Dhillon A. P, et al. The value of rectal biopsy in distinguishing self-limited colitis from early inflammatory bowel disease. Q J Med 1987;65:985-95.

39 Siproudhis L, Mortaji A, Mary JY, et al. Anal lesions: any significant prognosis in Crohn's disease? Eur J Gastroenterol Hepatol 1997;9:239-43.

40 Geboes K, Desreumaux P, Jouret A, et al. Diagnostic histopathologique de l'activité des maladies inflammatoires chroniques de l'intestin. Gastroenterol Clin Biol 1999;23:1062-73.

41 Pagenault M, Tron I, Alexandre JL, et al. Incidence des maladies inflammatoires du tube digestif en Bretagne (1994-1995). Gastroenterol Clin Biol 1997:21:483-90.

42 Surawicz CM. Serial sectioning of a portion of a rectal biopsy detects more focal abnormalities. A prospective study of patients with inflammatory bowel disease. Dig Dis Sci 1982;27:434-6.

43 Surawicz CM, Belic L. Rectal biopsy helps to distinguish acute self-limited colitis from idiopathic inflammatory bowel disease. Gastroenterology 1984;86:104-13.

44 Kramer K, Petras E, Kotanogi $H$, et al. Granulomatous versus nongranulomatous Crohn's disease: a clinicopathologic study of 185 cases. Lab Invest 1990;62:55A.

45 Schmitz-Moormann P, Pitner PM, Malchow H, et al. The granuloma in Crohn's disease. A bioptical study. Pathol Res Pract 1984;178:467-76.

46 Rotterdam H, Korelitz BI, Sommers SC. Microgranulomas in grossly normal rectal mucosa in Crohn's disease. Am J Clin Pathol 1977;67:550-4.

47 Geboes K, Van Den Oord J, De Wolf-Peeters C, et al. The cellular composition of granulomas in mesenteric lymph nodes from patients with Crohn's disease. Virchows Arch Pathol Anat 1986;409:679-92.

48 Chambers TJ, Morson BC. The granuloma in Crohn's disease. Gut 1979;20:269-74.

49 D'Haens G, Rutgeerts P, Geboes K, et al. The natural history of esophageal Crohn's disease: three patterns of evolution. Gastrointest Endosc 1994;40:296-300.

50 Danzy JT, Farmer RG, Sullivan BH, et al. Endoscopic features of gastroduodenal Crohn's disease. Gastroenterology 1976;70:9-13.

51 Korelitz BI, Waye JD, Kreuning J, et al. Crohn's disease in endoscopic biopsies of gastric antrum and duodenum. Am J Gastroenterol 1981;76:103-9.

52 Oberhuber G, Püspök A, Oesterreicher C, et al. Focally enhanced gastritis: a frequent type of gastritis in patients with Crohn's disease. Gastroenterology 1997; 112:698-706.

53 Mahadeva U, Martin JP, Patel NK, et al. Granulomatous ulcerative colitis: a re-appraisal of the mucosal granuloma in the distinction of Crohn's disease from ulcerative colitis. Histopathology 2002;41:50-5.

54 Lee FD, Maguire C, Obeidat W, et al. Importance of cryptolytic lesions and pericryptal granulomas in inflammatory bowel disease. J Clin Pathol 1997:50:148-52.

55 Makapugay LM, Dean PJ. Diverticular disease-associated chronic colitis. Am J Surg Pathol 1996;20:94-102.

56 Goldstein NS, Leon-Armin C, Mani A. Crohn's colitis-like changes in sigmoid diverticulitis specimens are usually an idiosyncratic inflammatory response to the diverticulosis rather than Crohn's colitis. Am J Surg Pathol 2000;24:668-75.

57 Gledhill A, Dixon MF. Crohn's-like reaction in diverticular disease. Gut 1998;42:392-5.

58 Jouret-Mourin A, Van Eeckout P, Haot J. Valeur du granulome et du microgranulome dans le diagnostic de la maladie de Crohn. Étude comparative entre la maladie de Crohn, la rectocolite ulcéro-hémorragique, la colite infectieuse et la colite aspécifique. Acta Endosc 1986;16:189-94. 
59 Sahmoud T, Hoctin-Boes G, Modigliani R et al. Identifying patients with a high risk of relapse in quiescent Crohn's disease. Gut 1995;37:811-18.

60 Colombel JF, Grandbastien B, Gower-Rousseau C, et al. Clinical characteristics of Crohn's disease in 72 families. Gastroenterology 1996;111:604-7.

61 Quinton JF, Sendid B, Reumaux D, et al. Anti-Saccharomyces cerevisiae mannan antibodies combined with antineutrophil cytoplasmic autoantibodies in inflammatory bowel disease: prevalence and diagnostic role. Gut 1998:42:788-91.

62 Reinshagen $M$, Loeliger C, Kuehnl P, et al. HLA class II gene frequencies in Crohn's disease: a population-based analysis in Germany. Gut 1996;38:538-42.

63 Tan WC, Allan RN. Diffuse jejunoileitis of Crohn's disease. Gut 1993;34:1374-8
64 Polito JM, Childs B, Mellits ED, et al. Crohn's disease: influence of age at diagnosis on site and clinical type of disease. Gastroenterology 1996; 111:580-6

65 Prantera C, Levenstein S, Capocaccia R, et al. Prediction of surgery for obstruction in Crohn's ileitis. A study of 64 patients. Dig Dis Sci 1987;32:1363-9

66 Ramzan NN, Leighton JA, Heigh Rl, et al. Clinical significance of granuloma in Crohn's disease. Inflamm Bowel Dis 2002;8:168-73.

67 Bataille F, Klebl F, Rummele P, et al. Histopathological parameters as predictors for the course of Crohn's disease. Virchows Arch 2003;443:501-7.

68 Bitton A, Peppercorn MA, Antonioli DA, et al. Clinical, biological, and histologic parameters as predictors of relapse in ulcerative colitis. Gastroenterology 2001;120:13-20.

\section{EDITOR'S QUIZ: GI SNAPSHOT}

\section{Chronic intermittent vomiting after scoliosis surgery}

\section{Clinical presentation}

A 12 year old girl presented with an 18 month history of intermittent postprandial vomiting and abdominal distension following scoliosis surgery. Her family history was unremarkable. On examination, her abdomen was slightly distended without tenderness. Bowel sounds were increased. Laboratory values were normal. Upper gastrointestinal study is depicted in fig 1.

\section{Question}

What is the diagnosis?

See page 281 for answer

This case is submitted by:

A Hokama, R Tomiyama, K Kishimoto, F Kinjo, A Saito First Department of Internal Medicine, University of the Ryukyus, Okinawa,

M Matayoshi Matayoshi Clinic, Okinawa, Japan

Correspondence to: Dr A Hokama, First Department of Internal Medicine, University of the Ryukyus, 207 Uehara, Nishihara, Okinawa 903-0215, Japan; hokama-a@med.u-ryukyu.ac.jp

doi: 10.1136/gut.2004.044313

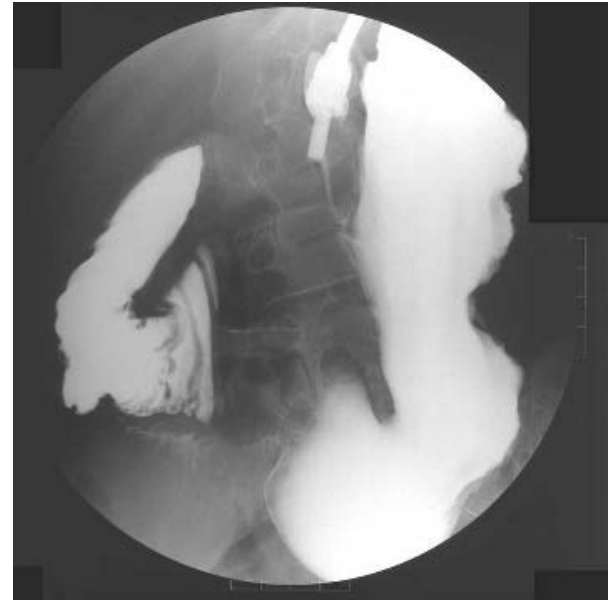

Figure 1 Barium contrast study of the duodenum. 